\title{
TRAÇANDO CATEGORIAS DE SUJEITOS LEITORES
}

\author{
AUTORA: BRUNA DE ALMEIDA COSTA \\ CO-AUTOR/ORIENTADOR: GABRIELA RODELLA DE OLIVEIRA
}

Resumo: A linguagem diz respeito à construção do sujeito, à elaboração de sua relação com o mundo, e os escritores podem contribuir para essa relação (PETIT, 2008). Acerca da leitura enquanto prática, que contribui, portanto, para a construção do sujeito e sua relação com o mundo, diversos são os movimentos que integram sua consolidação na vida dos leitores. A introdução desses leitores ao universo literário pode ser estabelecida na infância ou em outros estágios da vida, seja em ambientes como a biblioteca, a escola ou livrarias, de forma autônoma ou através de mediadores, como familiares, professores ou bibliotecários. Muitas são as nuances dos acontecimentos que contribuem para o estímulo e a solidificação dessa prática que, para Petit (2008), constitui-se em uma história de encontros. A leitura e o acesso aos livros se estabelecem de maneiras distintas na vida dos leitores, estando muitas vezes ligados a aspectos socioeconômicos e culturais. Buscando investigar essas diversas relações, este projeto de pesquisa de Iniciação Científica se propôs à análise de memoriais de leitura coletados no período de 2015 nas disciplinas de Metodologia do Ensino de Língua Portuguesa I e II da Faculdade de Educação da Universidade de São Paulo (FE-USP), com estudantes da Licenciatura em Letras. Para esses/as estudantes, a prática da leitura, mesmo que adquirida e fortalecida de formas diferenciadas (constituindo-se grande diversidade de perfis de leitores), é tida como atividade que modifica a vida daqueles que com ela entram em contato, proporcionando novos sentidos e significados para os sujeitos, para o mundo e para suas relações sociais. Nas análises, constatou-se que os processos de apropriação de práticas de leitura são compostos por aspectos importantes, como a mediação da leitura, entraves, dificuldades, bem como pôde-se notar o grande impacto que eles têm na transformação da subjetividade do leitor. Como referencial teórico, buscou-se apoio nas representações sociais de Serge Moscovici (2012); nas representações do livro e da leitura de Roger Chartier (2009); nas pesquisas sobre a leitura, os leitores e suas formações de Michèle Petit (2008; 2009); nos estudos sobre a sociologia da leitura de Lafarge e Segré (2010).

Palavras-chave: Prática de leitura literária; Formação de leitores; Representações Sociais. 